\title{
Nontuberculous Mycobacteria Isolated from Respiratory Specimens during Recent Two Years: Distribution and Clinical Significance
}

\author{
Min Kyoung Lee', Yiel Hea Seo ${ }^{2}$, Ji Hoon Jeong', Pil Whan Park², Kyung Hee Kim², \\ Jeong Yeal $\mathrm{Ahn}^{2}$, Jin Yong $\mathrm{Kim}^{3}$, Jeong Woong Park ${ }^{3}$ \\ ${ }^{1}$ School of Medicine, Gachon University School of Medicine, Departments of ${ }^{2}$ Laboratory Medicine, \\ ${ }^{3}$ Internal Medicine, Gachon University Gil Hospital, Incheon, Korea
}

\begin{abstract}
Background: The isolation of nontuberculous mycobacteria (NTM) has been increasing worldwide as well as its clinical importance. The aim of this study was to investigate the distribution and clinical significance of NTM that has been isolated from respiratory specimens during a recent two-year period at a tertiary hospital.

Methods: We analyzed respiratory samples that were obtained between January 2009 and December 2010 for AFB culture. We retrospectively reviewed the electronic medical records of these patients to obtain both clinical and radiologic information. NTM pulmonary disease was defined by using the guidelines provided by the America Thoracic Society/Infectious Diseases Society of America.

Results: Among the 1,601 specimens that resulted in a positive AFB culture, 310 (19.4\%) were NTM. In 189 patients, the most common isolate was $M$. aviumintracellulare complex (MAC) (127, 67.2\%), which was then followed by $M$. abscessus $(31,16.4 \%), M$. fortuitum $(10,5.3 \%)$, M. kansasii $(9,4.8 \%)$, and other
\end{abstract}

NTM species. Of these, $93(49.2 \%)$ patients were diagnosed with NTM pulmonary disease. MAC, M. abscessus, and $M$. kansasii were more virulent than the other species. None of the cases of NTM pulmonary disease were caused by $M$. fortuitum, M. chelonae, $M$. peregrinum, $M$. terrae complex, or $M$. gordonae. Conclusion: In Korea, the prevalence of NTM isolates is increasing, as are the cases of pulmonary disease. The pathogenic potential of NTM differs enormously by species and as a result the treatment of NTM lung disease depends on which species has caused the infection. The isolation and identification of NTM isolated from respiratory specimens are mandatory in order for clinical microbiology laboratories to make an accurate diagnosis and suggest the proper treatment of the NTM disease. (Korean $\mathbf{J}$ Clin Microbiol 2012;15:98-103)

Key Words: Mycobacteria, Nontuberculous mycobacteria, Respiratory specimen

\section{서 론}

비결핵 항산균(nontuberculous mycobacteria, NTM)은 결핵균 (Mycobacterium tuberculosis)과 나병균을 제외한 항산균을 말 한다. NTM은 결핵균에 비해 발병력(virulence)이 낮으며 사람 과 사람 사이에서는 전염되지 않는다. NTM에 의해 발생할 수 있는 인체질환은 폐질환, 림프절염, 피부질환, 파종성 질환 등 으로 다양하나 $90 \%$ 이상이 폐질환인 것으로 알려져 있다[1,2].

임상검체에서의 NTM 분리율은 지역에 따라 차이가 있는데 미국 등에서는 항산균 중 $50 \%$ 이상이 NTM으로 결핵균에 비 해 많은 것으로 보고되고 있다. 그러나 우리나라의 경우에는

Received 3 March, 2012, Revised 30 March, 2012

Accepted 17 April, 2012

Correspondence: Yiel Hea Seo, Department of Laboratory Medicine, Gachon University Gil Hospital, 1198, Guwol-dong, Namdong-gu, Incheon 420-709, Korea. (Tel) 82-32-460-3074, (Fax) 82-32-4603415, (E-mail) seoyh@gilhospital.com
1980년대 초에는 항산균의 97-98\% 이상이 결핵균이고 나머지 2-3\%만이 NTM으로 임상검체에서 분리되는 항산균의 대부분 이 결핵균이었다. 하지만 1990년대 이후에는 우리나라에서도 $\mathrm{NTM}$ 의 분리 비율이 지속적으로 증가하고 있는 것으로 보고되 고 있다[3,4].

$\mathrm{NTM}$ 에 의한 인체 질환 중 가장 흔한 형태가 폐질환이나 이 의 진단은 쉽지 않은 것으로 알려져 있다[1]. NTM은 물이나 토 양 등 자연환경에 흔히 존재하므로 객담 등 호흡기 검체에서 분리되었다 하더라도 오염 가능성을 배제하기 어려우며, 발병 력이 약하여 병의 진행경과가 늦기 때문에 진단에 어려움이 있 다. 따라서 NTM 폐질환의 유병율은 아직까지 정확하게 밝혀 져 있지는 않다[5].

본 연구는 최근 2년간 1,000 병상 규모의 한 대학병원 임상 미생물 검사실로 항산균 배양이 의뢰된 호흡기 검체 중에서 배 양 양성인 환자에서의 NTM 분리 비율과 균종 분포를 알아보 
고자 하였다. 또한 NTM이 분리된 환자 중 실제 NTM 폐질환 으로 진단되는 환자 비율, 치료유무 및 임상적 특징을 분석하 고자 하였다.

\section{대상 및 방법}

\section{1. 연구 대상}

2009년 1월부터 2010년 12월까지 2년간 임상미생물검사실 에 항산균 배양이 의뢰된 23,238개의 호흡기 검체를 대상으로 하였다. NTM이 분리된 환자들의 연령, 성별, 기저질환, 증상, 진단 당시 영상 소견, 치료 여부 등은 의무기록을 통해 후향적 으로 조사하였다.

\section{2. 항산균 배양검사와 균동정 검사}

항산균 배양검사는 $3 \%$ Ogawa 배지(Eiken, Tokyo, Japan)를 이용하여 $37^{\circ} \mathrm{C}$ 에서, 8 주간 배양하였다. 항산균 배양에 양성이 면 AdvanSure TB/NTM real time PCR kit (LG Life Sciences, Seoul, Korea)를 이용하여 결핵균과 NTM으로 구분하였다. NTM 균종 동정은 AdvanSure Mycobacteria Genotyping chip (LG Life Sciences) 혹은 유전자 염기서열분석을 통해 이루어 졌다. AdvanSure Mycobacteria Genotyping chip은 16S-23S rRNA Internal Transcribed Spacer (ITS) 부위를 이용하여 약 25 종의 항산균을 동정할 수 있는데 만약 이 검사에서 정확한 균 종 동정이 어려우면 $16 \mathrm{~S} \mathrm{rRNA}$ 혹은 $r p o B$ 유전자의 염기서열 분석을 통해 균종을 동정하였다.

\section{NTM 폐질환자 진단}

NTM이 분리된 환자 중 NTM 폐질환자로의 진단은 2007년 개정된 미국흥부학회와 미국감염학회의 진단 기준을 따랐다 [6]. 진단 기준은 임상적으로 호흡기 증상을 가지고 있으면서,
방사선학적으로 흉부 엑스레이에서 결절성 또는 공동성 병변 이 있거나 고해상도 전산화 단층촬영에서 다병소의 기관지확 장증 혹은 이에 동반된 다발성 소결절을 가진 환자에 적용된 다. 미생물학적 기준은 첫째, 최소한 2회 객담 검사에서 배양 양성을 보이거나 둘째, 최소한 기관지 세척액 1 회에서 배양 양 성인 경우나 셋째, 경기관지 폐생검 등 조직배양이 양성이거나 또는 조직검사에서 육아종 등 항산균 감염의 병리학적 증거가 있으면서 1회 이상 객담 또는 기관지 세척액에서 배양이 양성 인 경우이다. NTM은 분리되었지만 상기 진단기준을 만족하지 못한 경우는 비질환군(non-NTM disease)으로 정의하였다.

\section{4. 통계분석}

NTM이 분리된 환자 중 폐질환군(NTM disease)과 비질환군 (non-NTM disease)의 임상적 특징 비교는 SPSS version 12.0 (SPSS Inc, Chicago, IL, USA)을 이용하였다. 연속형 변수는 two-sample Student's t-test를 이용하였고 범주형 변수는 chisquare test를 이용하여 분석하였으며 유의수준 5\%에서 통계적 유의성 여부를 판단하였다.

\section{결 과}

\section{1. 항산균 배양 양성 검체에서 결핵균과 NTM의 분리 비율}

항산균 배양이 의뢰된 23,238 개의 호흡기 검체 중 1,601 검체 에서 항산균이 배양되어 총 $6.9 \%$ 의 양성률을 나타냈다. 항산균 배양 양성인 1,601검체 중 1,291 검체(80.6\%)에서 결핵균이 분 리되었고, 310검체(19.4\%)에서 NTM이 분리되었다.

\section{NTM이 분리된 환자에서의 균종 분포}

NTM이 분리된 310 개 검체 중 중복된 검체인 경우에는 첫 번째 검체만을 포함하여 총 189 명을 대상으로 균종 분포를 확

Table 1. Species distribution and clinical relevance of NTM species isolated from respiratory specimen

\begin{tabular}{lccc}
\hline \multicolumn{1}{c}{ Organisms } & No. of NTM isolated patient (\%) & No. of NTM disease (\%)* & No. of NTM disease with Tx (\%) ${ }^{\dagger}$ \\
\hline MAC (M. avium-intracellulare complex) & $127(67.2)$ & $69(54.3)$ & $44(63.8)$ \\
$\quad$ M. avium & $67(35.4)$ & $36(53.7)$ & $21(58.3)$ \\
M. intracellulare & $60(31.7)$ & $33(55.0)$ & $23(69.7)$ \\
M. abscessus & $31(16.4)$ & $15(48.4)$ & $10(66.7)$ \\
M. kansasii & $9(4.8)$ & $7(77.8)$ & $5(71.4)$ \\
M. asiaticum & $1(0.5)$ & $1(100)$ & $1(100)$ \\
M. celatum & $1(0.5)$ & $1(100)$ & 0 \\
M. fortuitum & $10(5.3)$ & 0 & 0 \\
M. chelonae & $4(2.1)$ & 0 & 0 \\
M. peregrinum & $3(1.6)$ & 0 & 0 \\
M. terrae complex & $2(1.1)$ & 0 & 0 \\
M. gordonae & $1(0.5)$ & $93(49.2)$ & $60(64.5)$ \\
Total & $189(100)$ & 0 & 0 \\
\hline
\end{tabular}

*Proportion of NTM disease to NTM isolated patient; ${ }^{\dagger}$ Proportion of NTM disease with treatment to NTM disease. Abbreviation: Tx, treatment. 
인하였다. M. avium-intracellulare complex (MAC)가 127명 (67.2\%)으로 가장 많이 분리되었는데, M. avium이 67명(35.4\%), M. intracellulare가 60명(31.7\%)이었다. 그 다음으로 M. $a b-$ scessus가 31명(16.4\%)에서 분리되었고 M. fortuitum이 10명 (5.3\%), M. kansasii 9명(4.8\%), M. chelonae 4명(2.1\%), M. peregrinum 3명(1.6\%), M. terrae complex가 2명(1.1\%)에서 분리되 었다. 그 외 M. asiaticum, M. celatum, 그리고 M. gordonae는 각 1 명(0.5\%)에서 분리되었다(Table 1$)$.

\section{NTM 폐질환자에서의 균종 분포, 균종에 따른 발병력 (vinulence), 치료여부}

NTM이 분리된 189 명 중 미국흉부학회와 감염학회의 진단 기준[7]을 이용하여 NTM 폐질환으로 진단된 경우는 93명 (49.2\%)이었다. NTM 폐질환자의 균종별 분포를 보면 MAC이 69 명으로 전체의 $74.2 \%$ 를 차지하였으며 그 다음으로 $M . a b-$ scessus가 15명(16.1\%), M. kansasii 7명(7.5\%), M. asiaticum 1명(1.1\%) 그리고 M. celatum 1명(1.1\%)이었다(Table 1).

각 균종별로 발병력에 차이를 나타냈는데 MAC은 분리된 127 명 중 69명(54.3\%)이 폐질환자로 진단되었고 M. abscessus 는 31명 중 15명(48.4\%), M. kansasii는 9명 중 7명(77.8\%)이 폐 질환으로 진단되었다. M. asiaticum과 M. celatum은 각 1 명에서 만 분리되어 모두 폐질환으로 진단된 반면 $M$. fortuitum, $M$. chelonae, M. peregrinum, M. terrae complex, M. gordonae가 분 리된 환자는 폐질환으로 진단된 경우는 없었다(Table 1).

NTM 폐질환으로 진단된 환자의 치료여부는 총 93명 중 60 명(64.5\%)에서 치료가 시행되었는데 균종 별로는 MAC이 분리 된 69명 중 44명(63.8\%), M. abscessus 15명 중 10명(66.7\%), M. kansasii 7명 중 5명(71.4\%), M. asiaticum 1명이었다(Table 1).

Table 2. Clinical characteristics of patients with lung diseases caused by NTM

\begin{tabular}{llcr}
\hline \multicolumn{1}{c}{ Variables } & $\begin{array}{c}\text { NTM disease } \\
(\mathrm{n}=93)\end{array}$ & $\begin{array}{c}\text { Non-NTM } \\
\text { disease }(\mathrm{n}=96)\end{array}$ & $P$ value \\
\hline Male & 49 & 54 & $0.623^{*}$ \\
Mean age & $63(32-85)$ & $66(29-90)$ & $0.112^{\dagger}$ \\
Positive AFB smear & 44 & 3 & $<0.001^{*}$ \\
Specimen & & & \\
$\quad$ Sputum only & 50 & 74 & $0.001^{*}$ \\
$\quad$ BAL only & 22 & 21 & $0.770^{*}$ \\
$\quad$ Both & 21 & 1 & $<0.001^{*}$ \\
Radiologic finding & & & \\
$\quad$ Consolidation & 35 & 27 & $0.164^{*}$ \\
$\quad$ Cavity & 28 & 12 & $0.003^{*}$ \\
$\quad$ Nodules & 42 & 34 & $0.172^{*}$ \\
$\quad$ Nodular bronchiectasis & 49 & 20 & $<0.001^{*}$ \\
\hline
\end{tabular}

${ }^{*} P$ values were obtained by chi-square test, $P<0.05 ;{ }^{\dagger} P$ value was obtained by two-sample Student's t-test, $P<0.05$.

\section{NTM 폐질환자로 진단된 환자들의 임상적 특징}

NTM 폐질환으로 진단된 93명의 환자 중 남성이 49명(52.7\%), 여성이 44명(47.3\%)이었다(Table 2). 진단 시 환자들의 평균 연 령은 63세(범위 32-85세)였으며, 항산균 도말염색에 양성을 나 타낸 경우는 44명(47.3\%)이었다. 균이 분리된 검체별로 보면 객담에서만 분리된 경우가 50명, 기관지 세척액에서만 분리된 경우가 22명, 그리고 양쪽 모두에서 분리된 경우가 21명이었 다. 흉부방사선검사 소견은 결절 기관지확장증(nodular bronchiectasis) 소견이 49명으로 가장 흔하였고 공동(cavity)을 나타 낸 경우는 28 명이었다.

NTM이 분리된 환자 중 NTM 폐질환군은 비질환군(nonNTM disease)에 비해 객담 항산균 도말 양성인 경우가 많았으 며 $(P<0.001)$, 객담과 기관지 세척액 모두에서 NTM이 분리된 경우가 많았고 $(P<0.001)$, 흉부 방사선 검사에서 공동(cavity) 혹은 결절 기관지 확장증(nodular bronchiectasis) 소견을 나타 낸 경우가 많았다 $(P=0.003, P<0.001)$. 반면 객담에서만 NTM 이 분리된 경우는 비질환군에서 많았다 $(P=0.001)$ (Table 2).

\section{고 찰}

최근 우리나라에서도 임상 검체에서 분리되는 항산균 중 $\mathrm{NTM}$ 의 비율이 증가하고 있다. 보고자에 따라 병원규모, 배양 방법, 연구 대상 등에 차이가 있어 정확하게 비교하기는 어렵 지만 분리되는 항산균의 약 $10-30 \%$ 정도가 NTM이고 그 비율 은 점차 증가하고 있다 $[4,7,8]$. 본 연구에서는 호흡기 검체를 대 상으로 하였는데 분리된 항산균의 $19.4 \%$ 가 NTM이었다. 이와 같이 임상검체에서 NTM분리가 증가하는 이유는 장기이식이 나 항암 치료를 받는 환자들의 증가로 인해 면역기능이 저하된 환자들이 늘어나고 있는 것과도 관련이 있으며 다른 한편으로 는 분자생물학적 검사기법의 발전으로 인해 임상미생물 검사 실에서 결핵균과 NTM의 구분이 비교적 쉽게 이루어지고 있는 것도 중요한 요인으로 생각된다[9].

$\mathrm{NTM}$ 은 현재까지 100 여 종 가까운 균종이 알려져 있으며 계 속 새로운 균종이 밝혀지고 있다[10]. 다양한 균종 중에서 인체 에서 분리되는 균종의 분포는 국가에 따라 그리고 국가 내에서 도 지역에 따라 다양하다. 미국과 일본의 보고에서는 가장 흔 히 분리되는 균은 M. avium-intracellulare complex (MAC)로 전체의 60-80\%를 차지하며 두 번째로 빈도가 높은 균은 $M$. kansasii로 10-20\%를 차지하고 그 외 M. abscessus, M. fortuitum, M. chelonae 등 신속 성장균은 $5 \%$ 미만을 차지하는 것으 로 알려져 있다[10-12]. 우리나라의 경우 2000년대 이후에 주로 보고되고 있는데 MAC이 50-60\%로 다른 나라와 같이 가장 흔 히 분리되고 있지만 두 번째로 분리되는 균은 M. abscessus로 다른 나라와 차이를 보이고 있다[3,13,14]. 본 연구 결과에서도 
$\mathrm{MAC}$ 이 전체 분리된 균의 $67.2 \%$ 를 차지하여 가장 높은 빈도를 나타냈으며 두 번째는 M. abscessus로 $16.4 \%$ 를 차지하였고 $M$. kansasii는 $4.8 \%$ 로 낮은 빈도를 나타내어 국내의 다른 보고들 과 유사한 양상을 나타냈다.

$\mathrm{NTM}$ 은 일상 생활 환경에 존재하는 균이므로 임상검체에서 분리되었다 하더라도 병원균이라고 단정짓기는 쉽지 않다. 미 국과 캐나다, 대만 등의 경우 NTM이 분리된 사람 중 약 40$50 \%$ 가 NTM 폐질환으로 진단되는 것으로 보고하고 있다 [11,15]. 국내의 경우는 보고자에 따라 차이가 있긴 하지만 과 거에는 약 $10-25 \%$ 에서만 NTM 폐질환으로 진단되었지만 최근 에는 30-40\% 정도로 증가된 것으로 보고되고 있다[16-19]. 본 연구에서는 NTM이 분리된 사람 중 $49.2 \%$ 가 NTM 폐질환자로 진단되어 국내의 다른 보고에 비해 높은 비율을 나타냈으며 미 국이나 다른 서구 국가와 유사한 양상을 나타냈다. 이렇게 비 교적 높은 비율을 나타낸 것은 2007년 개정된 폐질환 진단 기 준 중 미생물학적 기준이 과거에 비해 완화된 것도 하나의 원 인이 될 수 있으며 또 다른 이유로는 NTM 폐질환에 대한 관심 이 높아지면서 진단을 위해 좀 더 적극적인 노력을 기울이게 된 것도 중요한 요인으로 작용하였을 것이다.

NTM은 균종에 따라 실제 질환을 일으키는 발병력(virulence) 에 차이가 있는 것으로 알려져 있다. 본 연구에서 M. kansasii는 각 환자에서 분리된 9균주 중 7균주(77.8\%)에서 폐질환을 일으 켜 가장 높은 발병력을 나타냈으며 MAC과 M. abscessus도 각 각 54.3\%, 48.4\%로 비교적 높은 수치를 나타냈다. 반면 M. fortuitum, M. chelonae, M. peregrinum, M. terra complex 그리고 M. gordonae가 분리된 환자 중 NTM 폐질환자로 진단된 경우 는 한 예도 없었다. 이는 다른 연구결과와도 유사한 양상이었 으며[15], NTM 균종 동정은 그 자체로 분리된 균의 발병력 정 도를 파악하는데 매우 유용한 정보를 제공해 줄 수 있음을 알 수 있었다. 따라서 임상미생물 검사실에서는 호흡기 검체에서 NTM 균이 분리되었을 경우에 정확한 균종으로 동정하는 것이 매우 중요하다고 하겠다.

NTM 폐질환은 폐결핵과는 다르게 진단되었다고 해서 모두 치료를 시작해야 하는 것은 아니다. NTM 폐질환 중에는 증상 이 경미하고 경과가 매우 느리게 진행되어 충분한 시간을 두고 경과를 관찰하는 것이 필요한 경우도 있으며 각 환자에 따라 치료에 따르는 위험요인과 이득을 충분히 고려하여 결정해야 한다[9,20]. 본 연구에서도 NTM 폐질환으로 진단된 환자 93명 중 연구 기간 중에 치료를 시작한 환자는 60명(64.5\%)이었다. 나머지 환자들 중 15 명은 지속적으로 추적관찰 중이었으며, 18 명은 이후 추적관찰이 되지 않았다.

호흡기 검체에서 NTM이 분리되었을 때 실제 폐질환으로 진 단된 환자들은 객담 도말 양성, 단순흉부방사선 촬영상 공동의 존재, MAC 또는 M. abscessus가 동정된 경우 등과 연관성이 있는 것으로 보고되고 있다[21]. 본 연구에서는 NTM이 분리된
환자 중 폐질환으로 진단된 환자와 NTM은 분리되었지만 질환 은 일으키지 않은 비질환군의 임상적 특징들을 비교하였는데, NTM 폐질환군에서 객담 도말 양성, ㅎㅎㅇㅂㅜ 방사선 검사에서 공 동 혹은 결절 기관지 확장증 소견, 그리고 객담과 기관지 세척 액 모두에서 균이 분리된 경우가 많았으며 객담에서만 균이 분 리된 경우는 비질환군에서 많았다. 따라서 NTM 폐질환이 의 심되는 경우에는 객담과 함께 기관지 세척액도 동시에 검사하 는 것이 도움이 되겠으며 흉부 방사선 검사도 단순흉부방사선 촬영뿐만 아니라 고해상도 전산화단층촬영을 함께 시행하는 것이 정확한 진단에 도움이 될 것으로 생각된다.

NTM 폐질환은 균종 및 향부방사선 소견에 따라 임상양상에 도 차이가 있는 것으로 알려져 있다[20,22]. MAC에 의한 폐질 환은 상엽 공동형(apical fibrocavitary form)과 결절 기관지확장 증형(nodular bronchiectatic form) 등으로 구분된다. 상엽 공동 형은 오랜 기간의 흡연력이 있는 중년이상의 남성에서 주로 발 생하고, 만성폐질환이나 폐결핵 등 기저질환을 가지고 있는 경 우가 많다고 한다. 이에 반해 결절 기관지확장증형은 중년의 비흡연자 여성에서 잘 나타나며, 기저질환이 없는 경우가 많고 질환의 진행속도가 느린 것이 특징인 것으로 알려져 있다. 본 연구에서는 69 명의 MAC 환자 중 20 명에서 상엽 공동형을 나 타냈는데 이 중 13 명(65\%)이 남자였으며 12 명 $(60 \%)$ 이 폐결핵 의 과거력이 있었다. 결절 기관지확장증형을 나타낸 경우는 36 명으로 이 중 여성이 20명(56\%)이었고 폐결핵 과거력이 있는 환자는 11 명(31\%)으로 나타났다. M. abscessus에 의한 폐질환 은 MAC 폐질환의 결절 기관지확장증형과 유사한 형태를 나타 내는데, 본 연구에서도 15 명의 M. abscessus 폐질환자 중 11 명 (73\%)이 여성이었고 전부 비흡연자였으며 결절 기관지확장증 소견을 나타냈다. M. kansasii 폐질환은 임상특징과 영상소견이 폐결핵과 유사하며 주로 중년 남성에서 발생하고 영상소견상 상엽에 공동이 흔히 나타난다고 한다. 본 연구에서도 7명의 $M$. kansasii 폐질환자 모두 남성이었으며, 6 명에서 공동성 병변을 나타내어 매우 유사한 양상을 나타냈다.

결론적으로 우리나라에서도 항산균 배양양성인 호흡기 검체 중 NTM 분리 비율이 높아졌고 NTM 폐질환으로 진단되는 경 우가 증가하고 있다. 또한 NTM은 균종에 따라 발병력이 다르 고 병의 진행속도 및 치료도 달라지므로 임상미생물 검사실은 항산균 배양에서 양성인 경우 결핵균과 NTM의 구분뿐만 아니 라 NTM 균 동정을 시행하여 보고하는 것이 환자의 정확한 진 단 및 치료에 중요할 것으로 판단된다.

\section{참 고 문 헌}

1. Diagnosis and treatment of disease caused by nontuberculous mycobacteria. This official statement of the American Thoracic Society was approved by the Board of Directors, March 1997. Medical Section of the American Lung Association. Am J Respir 
Crit Care Med 1997;156:S1-25.

2. Management of opportunist mycobacterial infections: Joint Tuberculosis Committee Guidelines 1999. Subcommittee of the Joint Tuberculosis Committee of the British Thoracic Society. Thorax 2000;55:210-8.

3. Koh WJ, Kwon OJ, Yu CM, Jeon KM, Suh GY, Chung MP, et al. Recovery rate of nontuberculous mycobacteria from acid-fastbacilli smear-positive sputum specimens. Tuberc Respir Dis 2003; 54:22-32.

4. Lee JY, Choi HJ, Lee H, Joung EY, Huh JW, Oh YM, et al. Recovery rate and characteristics of nontuberculous mycobacterial isolates in a university hospital in Korea. Tuberc Respir Dis 2005;58:385-91.

5. Lee HW, Kim MN, Shim TS, Bai GH, Pai CH. Nontuberculous mycobacterial pulmonary infection in immunocompetent patients. Tuberc Respir Dis 2002;53:173-82.

6. Griffith DE, Aksamit T, Brown-Elliott BA, Catanzaro A, Daley C, Gordin F, et al; ATS Mycobacterial Diseases Subcommittee; American Thoracic Society; Infectious Disease Society of America. An official ATS/IDSA statement: diagnosis, treatment, and prevention of nontuberculous mycobacterial diseases. Am J Respir Crit Care Med 2007;175:367-416.

7. Park YS, Lee CH, Lee SM, Yang SC, Yoo CG, Kim YW, et al. Rapid increase of non-tuberculous mycobacterial lung diseases at a tertiary referral hospital in South Korea. Int J Tuberc Lung Dis 2010;14:1069-71.

8. Lee JK, Kwon HY, Kwon JK, Lee HJ, Lee DW, Lee YJ, et al. Recovery rate of nontuberculous mycobacteria and the clinical course of nontuberculous mycobacterial pulmonary disease at a secondary hospital. Tuberc Respir Dis 2009;67:199-204.

9. Glassroth J. Pulmonary disease due to nontuberculous mycobacteria. Chest 2008;133:243-51.

10. Koh WJ, Kwon OJ, Lee KS. Nontuberculous mycobacterial pulmonary diseases in immunocompetent patients. Korean J Radiol 2002; 3:145-57.

11. Marras TK and Daley CL. Epidemiology of human pulmonary infection with nontuberculous mycobacteria. Clin Chest Med 2002; 23:553-67.

12. Yim JJ, Park YK, Lew WJ, Bai GH, Han SK, Shim YS. Mycobac- terium kansasii pulmonary diseases in Korea. J Korean Med Sci 2005;20:957-60.

13. Ryoo SW, Shin S, Shim MS, Park YS, Lew WJ, Park SN, et al. Spread of nontuberculous mycobacteria from 1993 to 2006 in Koreans. J Clin Lab Anal 2008;22:415-20.

14. Simons S, van Ingen J, Hsueh PR, Van Hung N, Dekhuijzen PN, Boeree MJ, et al. Nontuberculous mycobacteria in respiratory tract infections, eastern Asia. Emerg Infect Dis 2011;17:343-9.

15. Chen CY, Chen HY, Chou CH, Huang CT, Lai CC, Hsueh PR. Pulmonary infection caused by nontuberculous mycobacteria in a medical center in Taiwan, 2005-2008. Diagn Microbiol Infect Dis 2012;72:47-51.

16. Koh WJ, Kwon OJ, Jeon K, Kim TS, Lee KS, Park YK, et al. Clinical significance of nontuberculous mycobacteria isolated from respiratory specimens in Korea. Chest 2006;129:341-8.

17. Choi SP, Lee BK, Min JH, Kim JH. Pathogenic classification and clinical characteristics of nontuberculous mycobacterial pulmonary disease in a national tuberculosis hospital. Tuberc Respir Dis 2005;59:606-12.

18. Shin S, Kim EC, Yoon JH. Identification of nontuberculous mycobacteria by sequence analysis of the $16 \mathrm{~S}$ ribosomal RNA, the heat-shock protein 65 and the RNA polymerase beta-subunit genes. Korean J Lab Med 2006;26:153-60.

19. Park CM, Heo SR, Park KU, Song J, Lee JH, Lee CT, et al. Isolation of nontuberculous mycobacteria using polymerase chain reaction-restriction fragment length polymorphism. Korean J Lab Med 2006;26:161-7.

20. Koh WJ and Kwon OJ. Diagnosis and treatment of nontuberculous mycobacterial lung disease. Korean J Med 2008;74:120-31.

21. Choi SP, Lee BK, Min JH, Kim JH. Pathogenic classification and clinical characteristics of nontuberculous mycobacterial pulmonary disease in a national tuberculosis hospital. Tuberc Respir Dis 2005;59:606-12.

22. Chung MJ, Lee KS, Koh WJ, Lee JH, Kim TS, Kwon OJ, et al. Thin-section CT findings of nontuberculous mycobacterial pulmonary diseases: comparison between Mycobacterium avium-intracellulare complex and Mycobacterium abscessus infection. J Korean Med Sci 2005;20:777-83. 
$=$ 국문초록=

\title{
최근 2년간 호흡기 검체에서 분리된 비결핵 항산균 분포와 임상적 의의
}

\author{
가천대학교 ${ }^{1}$ 의학전문대학원, 가천대 길병원 ${ }^{2}$ 진단검사의학과, ${ }^{3}$ 내과 \\ 이민경 ${ }^{1}$, 서일혜 ${ }^{2}$, 정지훈 ${ }^{2}$, 박필환 $^{2}$, 김경희 $^{2}$, 안정열 $^{2}$, 김진용 $^{3}$, 박정웅 $^{3}$
}

배경: 전세계적으로 비결핵 항산균(Nontuberculous mycobacteria, NTM)의 분리 및 이들에 의한 질환이 증가하고 있다. 본 연구에서는 최근 2년간 호흡기 검체에서 배양된 항산균 중 NTM 분리 비율과 균종 분포를 확인하고 이들 중 실제 NTM 폐질환으로 진단되는 환자들의 임상적 특징에 대해 알아 보고자 하였다.

방법: 2009년 1월부터 2010년 12월까지 2년간 임상미생물검사실로 항산균 배양이 의뢰된 호흡기 검체를 대상으로 하였 다. NTM이 분리된 환자들의 연령, 성별, 기저질환, 증상, 진단 당시 영상 소견, 치료 여부 등은 의무기록을 통해 후향적으 로 조사하였다. NTM 폐질환 진단은 2007년 개정된 미국흉부학회와 미국감염학회의 진단 기준을 따랐다.

결과: 항산균 배양 양성인 1,601검체 중 310검체(19.4\%)에서 NTM이 분리되었다. 이 중 중복된 검체를 제외한 총 189 명의 환자에서 MAC 127명(67.2\%), M. abscessus 31명(16.4\%), M. fortuitum 10명(5.3\%), M. kansasii 9명(4.8\%), 그 외 12명에서 기타 NTM 균종이 분리되었다. NTM이 분리된 189명 중 NTM 폐질환으로 진단된 환자는 93명(49.2\%)으로 균종별로 발병 력에 차이를 나타냈다. MAC, M. abscessus, M. kansasii는 높은 발병력을 나타낸 반면, M. fortuitum, M. chelonae, M. peregrinum, M. terrae complex, M. gordonae는 분리된 어떤 환자에서도 폐질환으로 진단된 경우는 없었다. 93명의 NTM 폐질 환자 중 60명(64.5\%)에서 연구기간 중에 치료가 시행되었다

결론: 우리나라에서도 항산균 배양양성인 호흡기 검체 중 NTM 분리 비율이 높아졌고 NTM 폐질환으로 진단되는 경우가 증가하고 있다. 또한 NTM은 균종에 따라 발병력이 다르고 병의 진행속도 및 치료도 달라지므로 임상미생물 검사실은 항산균 배양에서 양성인 경우 결핵균과 NTM의 구분뿐만 아니라 NTM 균동정을 시행하여 보고하는 것이 환자의 정확한 진단과 치료에 중요할 것으로 판단된다. [대한임상미생물학회지 2012;15:98-103]

교신저자 : 서일혜, 420-709, 인천시 남동구 구월동 1198

가천대 길병원 진단검사의학과

Tel: 032-460-3074, Fax: 032-460-3415

E-mail: seoyh@gilhospital.com 